\title{
The prevalence of fatty liver disease among diabetics in Mosul
}

\author{
Dhaher J. S. Al-Habbo*, Younise A. Khalaf**, Nabeel Alkhiat***, Ali K. Habash** \\ *Department of Medicine, College of Medicine, University of Mosul; ** Diabetes clinic, Dohuk Directorate \\ of Health, Dohuk; ***Nineveh Directorate of Health, Mosul.
}

(Ann. Coll. Med. Mosul 2009; 35(1): 50-57).

Received: $26^{\text {th }}$ Nov 2008; Accepted: $4^{\text {th }}$ May 2009.

\begin{abstract}
Objectives: To examine the occurrence of fatty liver disease in diabetic patients type 1 and 2 disease and to focus the attention in our locality about this serious condition.

Method: This prospective study of one hundred ten diabetic patients and one hundred patients as control was conducted in Ibn-Sena Teaching Hospital. Patients and control were referred from AlWafa Diabetic Center in Mosul, the outpatient department, and from the Medical Center of Mosul Medical College University of Mosul. All were referred for clinical assessment and for ultrasound examination of their abdomen.

Results: The patients include 34 patients with type 1 and 76 patients with type 2 diabetes. Of the 110 patients examined, $52.7 \%$ proved to have fatty infiltration in the liver by ultrasonography with no statistically significant difference between male and female.

Patients with type 2 diabetes mellitus were more vulnerable to develop fatty infiltration of the liver than type 1 diabetes mellitus, with statistically significant difference between them. Eighty six percent of patients with NAFLD were type 2 diabetes and $13.7 \%$ were type 1 diabetic disease. The control group have NAFLD in $8 \%$ only.

The age of the patients shows positive correlation and fatty infiltration in the liver increased with age. The longer the duration of diabetes mellitus makes the patients more likely to develop fatty infiltration in the liver.

The postprandial blood sugar level correlates significantly with the presence of fatty infiltration in the liver while the fasting blood sugar level does not.

Conclusion: Nonalcoholic fatty liver disease is common in our diabetic patients, occurs in both type1 and type 2 diabetes. Ultrasound may be used for epidemiological studies for detection of NAFLD in diabetics.
\end{abstract}

Keywords: Diabetes mellitus; fatty infiltration; Ultrasound.

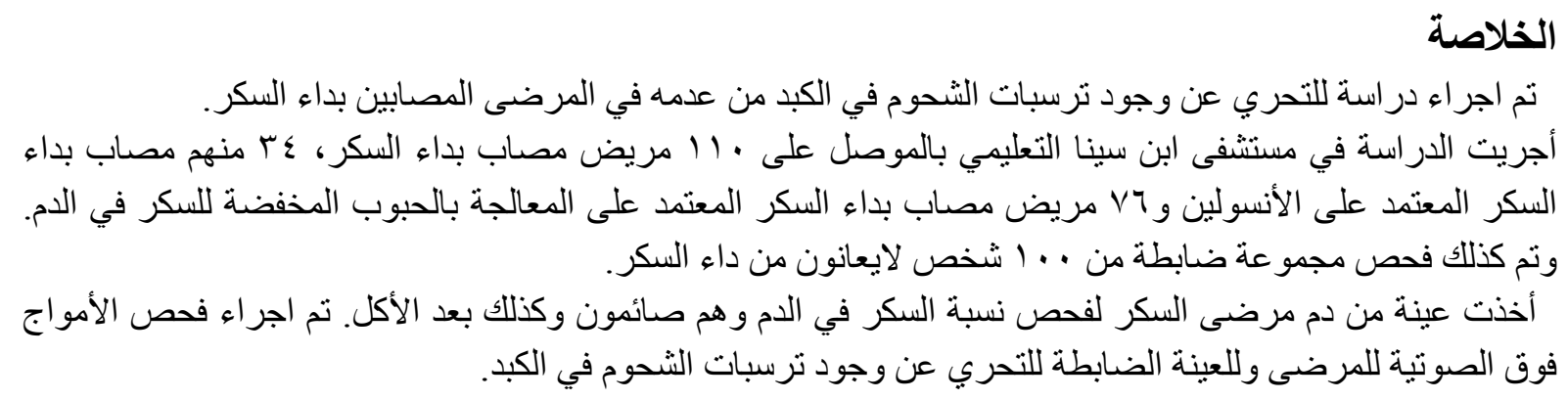


النتائج: تبين ان 52.7\% من العينة المفحوصة من مرضى السكر يعانون من وجود ترسبات الثحوم في الكبد، وتبين ان

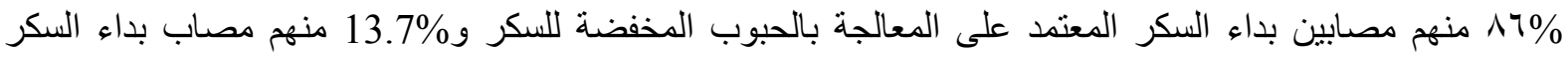

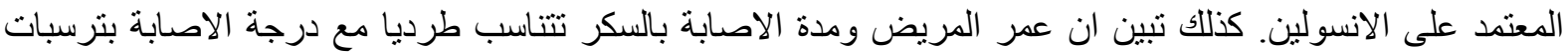

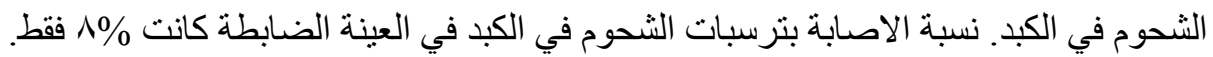

$\mathrm{N}$ onalcoholic fatty liver disease (NAFLD) was described first by Ludwig in $1980^{(1)}$. Most patients with nonalcoholic fatty liver disease are asymptomatic, but some may complain of fatigue and right upper quadrant abdominal fullness or pain with or without hepatomegaly ${ }^{(2)}$. The prevalence of NAFLD in the general population is estimated to be $20 \%$

(3). Nonalcoholic fatty liver disease now refers to a spectrum of diseases of the liver ranging from steatosis (i.e., fatty infiltration of the liver) to nonalcoholic steatohepatitis (NASH) (i.e., steatosis with inflammation and hepatocyte necrosis) to cirrhosis. The prevalence of nonalcoholic steatohepatitis (NASH) in the United States is $2-3 \%$, which makes $\mathrm{NASH}$ the potentially most common hepatic disease ${ }^{(4)}$.

Diabetes is an important independent predictor of severe hepatic fibrosis in NASH ${ }^{(5)}$. Up to one third of patients with NAFLD have diabetes or fasting hyperglycemia at the time of diagnosis with $\mathrm{NASH}^{(6-7)}$. Nonalcoholic fatty liver disease if untreated, will progress to $\mathrm{NASH}$ and end up by cirrhosis, because of that some of them will die in few years time ${ }^{(8)}$.The fibrosis of the liver may progress to cirrhosis, hepatocellular cancer and liver-related death ${ }^{(9,10)}$. The most frequent association of $\mathrm{NASH}$ is type 2 diabetes, although difficult-to-control insulin-dependent diabetes may also be affected $^{(11)}$.

In type 2 diabetes mellitus and in obesity, insulin resistance plays a fundamental role and is the most predisposing and reproducible factor in NASH ${ }^{(12)}$.

Ultrasonography of the liver has a sensitivity of 82 to 89 percent and a specificity of 93 percent for identifying fatty liver infiltrate ${ }^{(13,14)}$.

As it is known that nonalcoholic fatty liver (NAFL) is a medical condition that may progress to end-stage liver disease with the consequent development of portal hypertens- ion and liver failure ${ }^{(8)}$, this study aimed to examine the occurrence of fatty liver disease in diabetes mellitus type 1 and 2 disease and to focus the attention in our locality about this serious condition.

\section{Methods}

This was a prospective study for one hundred ten (110) diabetic patients and one hundred (100) patients as control group referred mainly from Al-Wafa Center in Mosul, the outpatient department, and from the Medical Center of Mosul Medical College University of Mosul, for clinical assessment and for ultrasound examination. The patients' agreements were taken by their verbal consent. The control group was selected randomly from patients consulting the radiology department for ultrasound of the abdomen.

The inclusion criteria and the clinical assessments of the patients and the control group were mainly to exclude the presence of obesity (Body Mass Index (BMI) more than of $\geq 30 \mathrm{Kg} / \mathrm{m}^{2}$ ) and to exclude any history of alcohol intake. There must be no evidence of chronic liver diseases, this specifically for history of hepatitis B (HBsAg) and hepatitis C. Furthermore there must be no history of chronic renal diseases.

All the ultrasound examinations were done in Ibn-Sena Teaching Hospital.

The age of the patients ranged from 11 to 73 years, 47 male and 67 female, the duration of diabetes was from 8 to 32 years. While the age of the control group patients ranged from 13 to 75 years, 52 males and 48 female with their age group distribution .

The patients include 34 patients with type 1 and 76 patients with type 2 diabetes mellitus, 43 patients on insulin therapy and 67 on oral hypoglycemic drugs. All the patients had their fasting and postprandial blood sugar done, HbA1c done only for 69 patients who agree to do the test in a private laboratory. 
The statistical calculations were done for all parameters and the different variables by using the means, SD, cross-tabulation, the chiSquare test (Fishers exact test).

\section{Results}

Of the 110 patients examined 58 (52.7\%) proved to have fatty infiltration in the liver by ultrasonography and $52(47.2 \%)$ patients had no fatty infiltration in the liver. There was no statistically significant difference between male and female with p-value >0.05 (NS) when tested by the cross-tabulation and the chiSquare test as in table (1):

Table (1): Fatty liver changes in correlation with the sex of the patients

\begin{tabular}{|c|c|c|c|c|c|}
\hline \multirow{2}{*}{ Sex } & \multicolumn{2}{|c|}{ Non-fatty liver } & \multicolumn{2}{|c|}{ Fatty liver } & \multirow{2}{*}{$p$-value } \\
\hline & No. & $\%$ & No. & $\%$ & \\
\hline Male & 24 & 51.1 & 23 & 48.9 & \multirow{2}{*}{$>0.05$ (NS) } \\
\hline Female & 28 & 44.4 & 35 & 55.6 & \\
\hline Total & 52 & & 58 & & \\
\hline
\end{tabular}

As it was expected, our study indicates that the type of diabetes mellitus correlates very well with the frequency of fatty infiltration in the liver and was found to have positive correlation with $\mathrm{p}$-value $<0.001$ by using the crosstabulation and the chi-Square test (Fishers exact test) as in table (2):

Table (2): Fatty liver changes in correlation with the type of diabetes mellitus

\begin{tabular}{||l|c|c|c|c|c||}
\hline \multirow{2}{*}{ DM } & \multicolumn{2}{|c|}{ Non-fatty liver } & \multicolumn{2}{c||}{ Fatty liver } & \multirow{2}{*}{ p-value } \\
\cline { 2 - 5 } & No. & $\%$ & No. & $\%$ & \\
\hline \hline Type 1 & 26 & 76.5 & 8 & 23.5 & \multirow{2}{*}{$<0.001$} \\
\hline Type 2 & 26 & 34.2 & 50 & 65.8 & \\
\hline Total & 52 & & 58 & & \\
\hline
\end{tabular}

Patients on oral hypoglycemic treatment as in type 2 diabetes mellitus were more vulnerable to develop fatty infiltration in the liver than those with insulin dependent type 1 diabetes mellitus with statistically significant difference between them with $p$-value of $<0.001$, although (23.5\%) of our patients with type 1 diabetes found to have NAFLD as shown in table (3):

Table (3): Fatty liver changes in correlation with type of treatment

\begin{tabular}{|l|c|c|c|c|c||}
\hline \multirow{2}{*}{ Type of treatment } & \multicolumn{2}{|c|}{ Non-fatty liver } & \multicolumn{2}{c|}{ Fatty liver } & \multirow{2}{*}{ p-value } \\
\cline { 2 - 5 } & No. & $\%$ & No. & $\%$ & \\
\hline \hline Insulin & 29 & 67.4 & 14 & 32.6 & \multirow{2}{*}{0.001} \\
\hline Oral & 23 & 34.3 & 44 & 65.7 & \\
\hline Total & 52 & & 58 & & \\
\hline
\end{tabular}

The age of the patients according to the age groups shows statistically significant correlation, the frequency of the development of fatty infiltration in the liver increases with the age of the patients as tested by using the cross-tabulation and the chi-Square test as in table (4): 
Table (4): Fatty liver changes according to age distributions

\begin{tabular}{|c|c|c|c|c|c|}
\hline \multirow{2}{*}{ Age groups (year) } & \multicolumn{2}{|c|}{ Non-fatty liver } & \multicolumn{2}{|c|}{ Fatty liver } & \multirow{2}{*}{$p$-value } \\
\hline & No. & $\%$ & No. & $\%$ & \\
\hline $11-20$ & 9 & 81.8 & 2 & 18.2 & \multirow{6}{*}{$<0.01$} \\
\hline $21-30$ & 8 & 66.7 & 4 & 33.3 & \\
\hline $31-40$ & 8 & 81.8 & 3 & 18.2 & \\
\hline $41-50$ & 11 & 52.4 & 10 & 47.6 & \\
\hline $51-60$ & 11 & 29.7 & 26 & 70.7 & \\
\hline$>60$ & 5 & 27.8 & 13 & 72.2 & \\
\hline Total & 52 & & 58 & & \\
\hline
\end{tabular}

As it was expected, the duration of diabetes mellitus makes the patients more likely to develop fatty infiltration in the liver with nearly $74 \%$ of the patients with fatty infiltration in the liver had their duration of diabetes for more than 10 years as indicated by the crosstabulation and the chi-Square test as in table (5):

Table (5): Fatty liver changes in correlation with the duration of diabetes mellitus

\begin{tabular}{|c|c|c|c|c|c|}
\hline \multirow{2}{*}{$\begin{array}{c}\text { Duration of DM } \\
\text { (year) }\end{array}$} & \multicolumn{2}{|c|}{ Non-fatty liver } & \multicolumn{2}{|c|}{ Fatty liver } & \multirow{2}{*}{$p$-value } \\
\hline & No. & $\%$ & No. & $\%$ & \\
\hline $6-9$ & 27 & 64.3 & 15 & 35.7 & \multirow{3}{*}{$<0.05$} \\
\hline $10-14$ & 11 & 42.3 & 15 & 57.7 & \\
\hline$\geq 15$ & 14 & 33.3 & 28 & 66.7 & \\
\hline Total & 52 & & 58 & & \\
\hline
\end{tabular}

Diabetic patients with fatty liver had higher mean postprandial blood sugar (PPBS) than those with no fatty liver, with a positive correlation between PPBS and NAFLD. Fasting blood sugar (FBS) level and the
HbA1c value showed no significant correlation with the development of NAFLD, from the calculation of the means, SD and the grouping variable between FBS and PPBS as shown in table (6):

Table (6): Fatty liver changes in correlation with FBS, PPBS and Hb1AC

\begin{tabular}{||l|c|c|c|}
\hline \multirow{2}{*}{ Parameters } & \multicolumn{2}{c|}{ Mean \pm SD } & \multirow{2}{*}{ p-value } \\
\cline { 2 - 3 } & Fatty liver & Non-fatty liver & \\
\hline \hline PPBS $(\mathrm{mmol} / \mathrm{L})$ & $21.10 \pm 5.65$ & $18.45 \pm 5.38$ & 0.01 \\
\hline FBS $(\mathrm{mmol} / \mathrm{L})$ & $13.68 \pm 7.33$ & $12.75 \pm 7.80$ & $>0.05(\mathrm{NS})$ \\
\hline HbA1c $(\%)$ & $9.51 \pm 1.59$ & $9.25 \pm 1.52$ & $>0.05(\mathrm{NS})$ \\
\hline
\end{tabular}

Of the 100 patients of the control group examined only $8(8 \%)$ proved to have fatty infiltration in the liver by ultrasonography, 5 female and 3 male patients as in table (7):

Table (7): Age distributions of the control group and the NAFLD among them.

\begin{tabular}{|c|c|c|c|c|}
\hline $\begin{array}{c}\text { Age } \\
\text { groups } \\
\text { (year) }\end{array}$ & $\begin{array}{c}\text { Numbe } \\
\text { rof } \\
\text { patients }\end{array}$ & $\begin{array}{l}\text { Fatty } \\
\text { liver }\end{array}$ & $\begin{array}{l}\text { Female } \\
\text { positive }\end{array}$ & $\begin{array}{c}\text { Male } \\
\text { positive }\end{array}$ \\
\hline $11-20$ & $\overline{8}$ & 0 & 5 & 3 \\
\hline $21-30$ & 11 & 0 & & \\
\hline $31-40$ & 22 & 0 & & \\
\hline $41-50$ & 27 & 2 & & \\
\hline $51-60$ & 16 & 3 & & \\
\hline$>60$ & 16 & 3 & & \\
\hline Total & 100 & $8(8 \%)$ & & \\
\hline
\end{tabular}




\section{Discussion}

Typical patient with NAFLD as had been described by Powell EE and coauthors, is a middle-aged woman ${ }^{(15)}$. In our studied sample 58 patients were labeled to have NAFLD by ultrasound, 23 male and 35 female patients with no statistically significant difference between male and female.

Males generally have greater abdominal visceral fat mass, which has a lipolytic nature and is in close proximity with the portal system. Furthermore, visceral fat and therefore free fatty acids, exposing the liver to large amounts of oxidizing substances or triglycerides which may either get stored (steatosis) or secreted into the circulation ${ }^{(16)}$. This phenomenon may explain our finding. Furthermore, epidemiologic studies of NAFLD suggest that men are at least as likely as women to have NAFLD or even higher $(6,17,18,24)$. All these findings are similar and support our results.

Fatty liver disease was found in (52.7\%) of our patients with diabetes, this result is the same as in other studies, where they found that NAFLD occurs in about 50 percent (range, 21 to 78 percent) of patients with diabetes $(6,7,19)$

Fifty out of the fifty eight diabetic patients with fatty liver disease, were type 2 diabetes mellitus (86\%) of all patients with NAFLD and form $(65.789 \%)$ of patients with type 2 diabetes mellitus. Furthermore, 44 patients on oral hypoglycemic therapy have NAFLD which makes $75.9 \%$ of the patients with NAFLD, this difference in the number is because some of our patients on insulin therapy were originally type 2 diabetes, these findings were similar to others ${ }^{(6,7,20)}$.

Type1 diabetes is less likely to cause NAFLD but in our patients $13.7 \%$ of those with NAFLD were type 1 diabetes, which form nearly (23.5\%) of our patients with type 1 diabetes. These findings are different from our control group where NAFLD are found in $8 \%$ only. Although our control group is not big enough to represent the Iraqi population, our control group had a lower figure of NAFLD if we compare it with other studies ${ }^{(3)}$. The prevalence of NAFLD in type 1 diabetes in our study is in agreement with other studies where they found even children with type 1 diabetes mellitus may develop NAFLD, although our figure is somewhat higher probably due to the older age group among our adult patients and even among the children in our patients $(11,21,22)$. The established risk factors for NAFLD in children include obesity, insulin resistance, and diabetes ${ }^{(23)}$. Although the evidence of insulin resistance is common among type 2 diabetic in youth, it is also seen in $30 \%$ of youth with type 1 diabetes ${ }^{(35)}$. These findings may explain the prevalence of fatty liver in our studied patients with type 1 diabetic disease .

The postprandial blood sugar (PPBS) level correlates significantly with the presence of NAFLD, while the fasting blood sugar (FBS) level and the HbA1c value showed no significant correlation with the development of NAFLD. The PPG is a marker of glycemic burden and is as predictive or more predictive of the risk for complications of diabetes when compared with $\mathrm{FPG}^{(36)}$. The positive correlation between fatty liver and the level of postprandial blood sugar may indicate the presence of insulin resistance in this group of patients. Insulin resistance is a major feature of NAFLD that, in some patients, can progress to steatohepatitis ${ }^{(37)}$. The HbA1c level was done only in about $62 \%$ of our patients, therefore its value may be not truly representative of the its real correlation with the NAFLD.

Ultrasonography as a diagnostic test had been found to have a sensitivity of 89 percent and a specificity of 93 percent in detecting NAFLD ${ }^{(13,25)}$.

Nonalcoholic fatty liver disease is usually diffusely distributed or occasionally focal. Consequently, CT scans may be misinterpreted as malignant liver masses ${ }^{(26)}$. Few studies compare ultrasound and CT scans for diagnostic accuracy in NAFLD and they were nearly the same with a sensitivity of $75 \%, 80 \%$ respectively ${ }^{(27)}$.

The histopathological diagnosis by liver biopsy is logically the golden standard method for detection of NAFLD, but this requires the equipments, laboratory investigations, 
preparation of the patients by doing blood group and cross match, the expertise in doing liver biopsy and the patient's consent because of the expected complication of this rather invasive and sometimes harmful procedure. Furthermore, recent studies have questioned its reliability because it may frequently miss the diagnosis. More than $24 \%$ of proven NAFLD may be missed if only one biopsy sample had been taken ${ }^{(28)}$.

For all the above reasons we decided that our radiologist should examine our patients by using the new version of ultrasound (MEDISON 8000 LIVE KOREA) which is available in Ibn-Sena Teaching Hospital, as this procedure is available and affordable free off charge to all our patients.

Hepatic magnetic resonance spectroscopy imaging is more sensitive than ultrasound for detecting minor degrees of steatosis and allows a quantitative assessment of fatty infiltration of the liver ${ }^{(29,30)}$.

This rather small study indicates that NAFLD is present in our diabetic patients involving more than $50 \%$ of them. These findings should raise the alarm for the problem of NAFLD in our diabetic patients and to look for all the available means to prevent and/or to treat the high risk group patients. Furthermore, increased prevalence of liver disease occurs in both type 1 and type 2 diabetic patients, resulting in an increased prevalence of cirrhosis, portal hypertension, liver failure, steatosis, iron overload, and even hepatoma (31). Nonalcoholic fatty liver disease some times follows a relatively benign course and remains stable ${ }^{(32)}$. However NAFLD is the most common cause of elevated liver enzymes in adults in the United States and the most common cause of cryptogenic cirrhosis ${ }^{(33,34)}$.

\section{Conclusion}

Nonalcoholic fatty liver disease is common in our diabetic patients, occurs in both sexes and in type 1 and type 2 diabetes mellitus. Ultrasound may be used for epidemiological studies for detection of NAFLD in diabetics, general population and obese people.

\section{References}

1. Ludwig J, Viggiano RT, McGill DB. Nonalcoholic steatohepatitis: Mayo Clinic experiences with a hitherto unnamed disease. Mayo Clin Proc 1980; 55: 342-8.

2. Sanyal AJ; American Gastroenterological Association. AGA technical review on nonalcoholic fatty liver disease. Gastroenterology 2002;123:1705-25.

3. El-Hassan AY, Ibrahim EM, Al-Mulhim FA, Nabhan AA, Chamas MY. Fatty infiltration of the liver: analysis of prevalence, radiological and clinical features and influence of patients management. $\mathrm{Br}$ Radiology 1992; 65: 774-8.

4. Jick SS, Stender M, Myers MW. Frequency of liver disease in type 2 diabetic patients treated with oral antidiabetic agents.Diabetes Care 1999;2:1067-71.

5. Angulo P, Keach JC, Batts KP, Batts KP, Lindor KD. Independent predictors of liver fibrosis in patients with nonalcoholic steatohepatitis. Hepatology 1999; 30: 1356-62.

6. Bacon BR, Farahvash MJ, Janney CG, Neuschwander-Tetri BA. Nonalcoholic steatohepatitis: an expanded clinical entity. Gastroenterology 1994; 107: 11039.

7. James OFW, Day CP. Nonalcoholic steatohepatitis (NASH): a disease of emerging identity and importance. $\mathrm{J}$ Hepatol 1998; 29: 495-501.

8. Matteoni CA, Younossi ZM, Gramlich T, Boparai N, Liu YC, McCullough AJ. Nonalcoholic fatty liver disease: a spectrum of clinical and pathological severity. Gastroenterology 1999; 116: 1413-9.

9. El-Serag HB, Tran T, Everhart JE: Diabetes increases the risk of chronic liver disease and hepatocellular carcinoma. Gastroenterology 2004; 126:460-468.

10. Dam-Larsen S, Franzmann $M$, Andersen IB, Christoffersen $P$, Jensen LB, Sorensen $\mathrm{TI}$, Becker $\mathrm{U}$, Bendtsen $\mathrm{F}$ : Long term prognosis of fatty liver: risk of chronic liver disease and death. Gut 2004;53:750-755. 
11. Lenaerts J, Verresen L, Van Steenbergen W, Fevery J. Fatty liver hepatitis and type 5 hyperlipoproteinemia in juvenile diabetes melllitus. Case report and review of the literature. J Clin Gastroenterol 1990; 12 : 93-7.

12. Belfiore $F$, lannello $S$. Insulin resistance in obesity: metabolic mechanisms and measurement methods. Mol Genet Metab 1998; 65: 121-8.

13. Joseph AE, Saverymuttu $\mathrm{SH}$, al-Sam $\mathrm{S}$, Cook MG, Maxwell JD. Comparison of liver histology with ultrasonography in assessing diffuse parenchymal liver disease. Clin Radiol 1991;43:26-31.

14. Hultcrantz R, Gabrielsson N. Patients with persistent elevation of aminotransferases: investigation with ultrasonography, radionuclide imaging and liver biopsy. J Intern Med 1993;233:7-12.

15. Powell EE, Cooksley WG, Hanson R, Searle J, Halliday JW, Powell LW. The natural history of nonalcoholic steatohepatitis: a follow-up study of fortytwo patients for up to 21 years. Hepatology 1990;11:74-80.

16. Wolf AM, Busch B, Kuhlmann HW, Beisiegel $U$. Histological changes in the liver of morbidly obese patients: correlations with metabolic parameters. Obes Surg. 2005; 15: 228-37.

17. Nomura H, Kashiwagi S, Hayashi J, Kajiyama W, Tani S, Goto M. Prevalence of fatty liver in a general population of Okinawa, Japan. Jpn J Med 1988;27:142149.

18. Luyckx FH, Desaive C, Thiry A, et al. Liver abnormalities in severely obese subjects: effect of drastic weight loss after gastroplasty. Int $\mathrm{J}$ Obes Relat Metab Disord 1998;22:222-226.

19. Creutzfeldt W, Frerichs $H$, Sickinger $K$. Liver diseases and diabetes mellitus. Prog Liver Dis 1970;3:371-407.

20. Wanless JR, Lentz JS: Fatty liver hepatitis (steatohepatitis) and obesity: an autopsy study with analysis of risk factors. Hepatology1990; 12:1106-10.
21. Rashid M, Roberts EA. Nonalcoholic steatohepatitis in children. J Pediatr Gastroenterol Nutr 2000;30:48-53.

22. Manton ND, Lipsett J, Moore DJ, Davidson GP, Bourne AJ, Couper RTL. Nonalcoholic steatohepatitis in children and adolescents. Med J Aust 2000;173:476479.

23. Schwimmer JB, Deutsch R, Rauch JB, Behling C, Newbury R, Lavine JE. Obesity, insulin resistance, and other clinicopathological correlates of pediatric nonalcoholic fatty liver disease. $\mathrm{J}$ Pediatr. 2003;143:500 -505.

24. Clark JM, Brancati FL, Diehl AM. The prevalence and etiology of elevated aminotransferase levels in the United States. Am J Gastroenterol. 2003;98:960 $-967$.

25. Norma C Mcavoy, James W Ferguson, Ian W Campbell and Peter C Hayes. Nonalcoholic fatty liver disease: natural history, pathogenesis and treatment BJDiabetes\&Vascular Disease $2006 ; 6$ :ISS 6 . 251-260.

26. Debaere C, Rigauts $H$, Laukens $P$. Transient focal fatty liver infiltration mimicking liver metastasis. J Belge Radiol 1998;81:174-175.

27. Saadeh S, Younossi ZM, Remer EM, Gramlich T, Ong JP, Hurley M, et al. The utility of radiological imaging in nonalcoholic fatty liver disease. Gastroenterology 2002; 123: 745-750

28. Ratziu V,Charlotte F,Heurtier A et al.Sampling variability of liver biopsy in nonalcoholic fatty liver disease.Gastroenterology2005;128:1898906.

29. Longo R, Pollesello P, Ricci C, et al. Proton MR spectroscopy in quantitative in vivo determination of fat content in human liver steatosis. J Magn Reson Imaging 1995;5:281-285

30. Fishbein M, Castro F, Cheruku S, Jain S, Webb B, Gleason T, et al. J Clin Gastroenterol 2005; 39: 619-625.

31. Albright, Eric S. MD; Bell, David S. H. MB, FACE: The Liver, Liver Disease, and 
Diabetes Mellitus. The Endocrinologist 2003;13(1): 58-66 .

32. Teli M, Oliver FW, Burt AD, et al. The natural history of nonalcoholic fatty liver: a follow up study. Hepatology 1995; 22:1714-1717.

33. Angulo $P$. Nonalcoholic fatty liver disease. N Engl J Med 2002;346: 1221-31.

34. Clark JM, Diehl AM. Nonalcoholic fatty liver disease: an underrecognized cause of cryptogenic cirrhosis. JAMA 2003; 289:3000-4.

35. Zachary T. Bloomgarden, MD. Nonalcoholic Fatty Liver Disease and Insulin Resistance in Youth .Diabetes Care 2007 ;30:1663-1669.
36. Avignon A, Radauceanu A, Monnier L. Nonfasting plasma glucose is a better marker of diabetic control than fasting plasma glucose in type 2 diabetes. Diabetes Care. 1997;20:1822-1826.

37. Kristina M.Utzschneider and Steven E. Kahn. The role of insulin resistance in nonalcoholic fatty liver disease.The J Clin Endocrinology \& Metabolism 2006; 91(12): 4753-4761 